\title{
Dynamics of self-efficacy in the context of the problem of professional formation of future teacher
}

\author{
Fatima Baybanova \\ Karachay-Cherkess state University named after U. D. Aliyev, 369202 Karachaevsk, \\ Russian Federation
}

\begin{abstract}
The problem of dynamics of development of self-efficacy at students of pedagogical specialties is considered. The analysis of the theoretical material on the topic is under study. And we try to reveal the considered types, levels and conditions of formation of perceived selfefficacy in future teachers. We present the results of empirical research of dynamic characteristics of self-efficacy of a sample of 83 students identified statistical indicators of development of subject self-efficacy and self-efficacy in communicating their relationship with motivation of choice of profession and level of self-evaluation. The integrity, dynamism and multicomponent self-efficacy; nonlinear nature of its development at different stages of training are revealed.
\end{abstract}

\section{Introduction}

The realities of the modern world impose increased requirements for the actualization of internal resources that contribute to the growth of success and productivity of selfrealization of the individual. For a person aspiring to professional self-realization, it is fundamentally important to be able to independently determine their potential and cognitive qualities that allow the most effective to build activities and implement life tasks. As such the metacognitive component that allows a person to analyze the capabilities of their cognitive system and make the best use of them, modern researchers recognize selfefficacy.

Initially, the development of this phenomenon and the vast majority of studies of the phenomenon of self-efficacy took place abroad.

In the historical context, self-efficacy as an integrative personal education, as a cognitive construct, was first developed within the framework of the theory of social learning by A. Bandura (A. Bandura, 2000). According to the author, "self-efficacy is a person's perception of his ability to act in present situations, successfully which is based on the principle of mutual determination of personal factors, behavioral activity and environment, a person's beliefs about his ability to manage events that affect life» [1]. According to the author of the theory A. Bandura, the subject models the situation and expects a positive result of their actions, which is a confirmation of its effectiveness and leads to the formation of perceived self-efficacy. In accordance with the theme of this study, the most valuable the studies of self-efficacy in the field of pedagogical psychology 
for us were, carried out by western and domestic scientists. Foreign researchers of selfefficacy, headed by A. Bandura, have widely revealed the relationship of self-efficacy with the motivation of learning and the effectiveness of educational activities (A. Bandura, 2000). As it turned out, the perceived self-efficacy leads to increased perseverance of students in learning activities, and, accordingly, to an increase in motivation and interest in learning [3].

In the domestic psychological problem of studying self-efficacy was insufficiently covered. The development of this problem involved Krichevsky R. L, who defines selfefficacy as "... the belief of people in their ability to mobilize motivation, intellectual resources, behavioral efforts to control events that affect their lives" [6]; Gordeeva T. O."self-efficacy is the belief of the subject in his ability to cope with a certain activity"[5]; Gaidar M. I. - "self-efficacy is a combination of a person's ideas about their capabilities and abilities to be productive in the implementation of the upcoming activities, communication, and his confidence that he will be able to realize themselves in them and achieve the expected objective and subjective effect" [4].

\section{Problem statement}

Modern living and working conditions impose strict requirements to the personal and professional qualities of a future specialist, especially the teacher. As in any other field, pedagogy requires highly effective professionals who are able to adequately assess their capabilities and the results of their activities [9]. Studies show that such important indicators of life activity as professional and personal growth, emotional States, the level of motivation, the ability to treat failures as a natural stage of professional growth and, having drawn conclusions, to work further depend on the ideas about one's own self-efficacy [2]. Therefore, self-efficacy is one of the conditions for successful adaptation. Based on the above, it becomes obvious the that relevance of the study of self-efficacy of students: the problem of adaptation to new conditions of learning, and often, and living, the development of programs of psychological support of professional development of future specialists are relevant for each higher education institution.

Professional self-efficacy of the teacher consists of such terms as activity, communicative and personal self-efficacy.

Communicative self-efficacy of a teacher in the professional sphere is a combination of his ideas that he has such communicative skills and experience that will allow him to be competent in professional communication, and confidence that he will be able to effectively implement these skills and experience in situations of interaction with people.

Personal self-efficacy of the teacher is a confidence in his professional competence, through which he assumes to perform successfully the tasks facing him as a specialist and build certain strategies of behavior in working with people, i.e., in fact, it is a professional tool.

\section{Purpose of research}

The aim of this study was to study the dynamics of self-efficacy of future teachers, to identify correlations between the characteristics of different types of self-efficacy.

\section{Method of research}

To identify the features of the dynamics of personal self-efficacy of students of pedagogical specialties in the process of learning at the University we have used the following methods: 
test-questionnaire of self-efficacy. Maddux and M. Scheer in the adaptation of A. V. Boyarintseva; the scale of General self-efficacy of R. Schwarzer and M. Jerusalem, adapted by V. G. Romek in 1996.

\section{Description of the research}

This article appeared as a result of an empirical study of the psychological features of the development of self-efficacy of future teachers at the stage of higher education, which was conducted from 2017 to 2019.

The research was carried out on the basis of Karachay-Cherkess state University. The sample was formed by 83 students of pedagogical specialties of 1-5 courses of three faculties: physical and mathematical, philological and pedagogical.

Our research was conducted in two stages:

1. Analysis of theoretical literature in order to identify the most significant properties for the study of the dynamics of self-efficacy of future teachers at various stages of University education; selection of methods of empirical research.

2. The ascertaining part of the experiment, which included the study of the dynamics of personal self-efficacy of students of pedagogical specialties at the stage of higher education and aimed to empirically test the hypothesis about the nonlinear nature of the dynamics of students of 1-5 courses. By results of the conducted experiment the comparative analysis of dynamics of development of personal self-efficacy with features of dynamics of activity and communicative self-efficacy (determined by means of Maddux-Scheer questionnaire) was carried out.

The selected methods have been tested in the dissertation research of Russian psychologists on the problem of self-efficacy.

The level of personal self-efficacy of students-future teachers was digitalized with the help of the self-efficacy test J. Maddux and M. Scheer. According to the data obtained, the subjects are divided into 3 groups depending on the level of development of their personal self-efficacy: low level of self-efficacy, medium and high level of personal self-efficacy.

\section{Conclusion}

The results of the testing revealed almost the same number of students with low and high levels of self - efficacy-about $15.0 \%$. The first are not sure of their ability to show professional skills in working with children, as they hardly realize the presence of professionally important qualities of a teacher. The latter are absolutely sure that they have all the necessary for future professional activity professionally important qualities and are convinced that they are able to update them if necessary. About $68 \%$ of the subjects found an average level of personal self-efficacy. This contingent of students has a fairly complete understanding of the professionally important qualities of the teacher and is fully aware of the presence of most of these qualities but, in our opinion, are not entirely confident in their ability to effectively apply them in their professional activities. The fact that the majority of students identified an average level of personal self-efficacy, naturally, as shown by theoretical analysis, the formation of perceived self-efficacy occurs as a result of successfully carried out professional activities, respectively, the a high level of self-efficacy in the process of preparation for work is not necessary.

During the study revealed a wavy, non-linear nature of the development dynamics of self-efficacy in students: 1st, 3rd and 5th years of study marked as a kind of crisis of selfefficacy, these periods of peak reduction level of efficacy. Gaydar M.I. came to the same conclusions in his study: "in the 1st year of personal self-efficacy of future 
teachers is not naturally expressed. In the 3rd year, it is also not high enough because of the contradiction: the emerging idea of what professionally important and personal qualities a teacher should have, and their own professionally important qualities. In the 5th year, students come to the realization of the approaching completion of studies. At the same time, the prospect of an early start of independent professional activity in some of them causes anxiety and doubt in their abilities, as a result of which low rates for all types of selfefficacy are diagnosed in one sixth of graduates [3]." But still, this figure is lower in the 5 th year than in the 1st and 3rd courses. During the first three years of training, as a rule, there is a crisis of professional development, the result of which is a decrease in the level of personal self-efficacy of a significant part of future teachers.

Students of the 2 nd and 4th courses are more likely to be diagnosed with a high level of personal self-efficacy - about a quarter of the total. With the development of most disciplines and the formation of ideas about some professional competencies, personal selfefficacy indicators increase, for most students (about 27\%)this happens by the end of the second year. 4th year students are also diagnosed with a high level of personal self-efficacy ( $28.1 \%$ of students). This is due, in addition to the development of basic disciplines, with the passage of practices, educational and pedagogical, "contributing to the formation of confidence in the presence of professionally important qualities and their ability to use them in the future and as a functional means to achieve success in the profession" [3].

Personal self-efficacy is manifested in two areas: activity and communication.

The vast majority of future teachers - $83.1 \%$ - demonstrate an average level of activity self-efficacy. As a rule, they believe that they have all the necessary competencies to perform the activities that they plan to engage in. The number of students with a high level of self - efficacy in the activity was small-only $6 \%$ of the sample, but these students are convinced of their future success and competitiveness in the profession and are confident that the knowledge, skills, skills, experience acquired during the practical work, they will be able to apply in such activities in the future.

It should be noted that the lowest percentage of students with a high level of selfefficacy was identified in the first $(0.4 \%)$ and fifth years $(1.3 \%)$. Freshman year, probably. It is explained by the complexity of the adaptation period and vague ideas about their future specialty. Fifth-year students, on the contrary, are well aware of the requirements of the modern labor market, which raises doubts about their competence and demand.

As can be seen, during the entire period of study at the University, the average level of activity self-efficacy prevails. There is also a correlation in the distribution of students with low and high levels of activity self-efficacy and personal self-efficacy.

Now about the results of the study of communicative self-efficacy. Approximately one fifth of the sample has a low level of development of this quality. These students are not sure whether they have communication skills and the ability to establish contacts with others. Only one-eighth of the tested students have a high level of communicative effectiveness. As a rule, these students adapt easily in society, are able to build relationships with others and are confident in their ability to communicate. The rest of the tested students, about $68 \%$, demonstrated an average level of communicative self-efficacy. These are students who believe that they have good communication skills and will be able to use them in future activities.

As we can see, during all five courses, the average level of self-efficacy in both activity and communication dominates.

Summarizing the results of the study of personal self-efficacy of students, we came to the conclusion that the majority of future teachers diagnosed by us have an average level of personal and communicative self-efficacy. That's about $75 \%$ of the sample. The remaining $25 \%$ show opposite variants of self-efficacy development-low or high. Moreover, a low level of activity self-efficacy is more common among students of the 1st, 3rd and 5th 
courses, and a high level-the 2nd and 4th.dynamics of development of communicative selfefficacy differs from the pattern of development of personal self-efficacy: the low level of development are diagnosed at the 2nd and 3rd courses, high - on 1-m and 5-m, that is, by the time of completion of the training, the level of communicative self-efficacy becomes higher.

So, with the help of research of personal self-efficacy of students-future teachers the following statistically confirmed facts are revealed:

1) the majority of students of pedagogical specialties is dominated by the average level of personal self-efficacy, this figure does not depend on what course students study; students of the $1 \mathrm{st}, 3 \mathrm{rd}$ and 5 th courses often have a low level of personal self-efficacy; students of the 2 nd and 4 th courses often have a high level of personal self-efficacy.

2) the average dynamics of personal self-efficacy of future teachers in the learning process at the University is non-linear, wave-like manner, for example: for 1st year students in the weight have low level of personal self-efficacy, on the 2 nd course the number of students with a high level of personal self-efficacy increases, respectively, the overall level is changing in the direction of increasing same frequency; 3-year is a crisis, the level of efficacy is reduced; on the 4th, he we are again seeing growth, 5-year newly diagnosed reduction in the level of efficacy.

Thus, the dynamics of the level of self-efficacy of the student as a subject of cognitive activity is directly related to the perception of their own competence, with changes in personal characteristics and with the stages of training.

\section{References}

1. A. Bandura, Social learning Theory. (Eurasia, SPb., 2000)

2. F. A. Baybanova, Scientific journal RAE, 11(12), 217-225 (2014)

3. R. L Krichevsky, Acmeology, 1, 47-53 (2001)

4. T. O. Gordeeva., E. A. Shepeleva, Vesti Mosk.Univ., 14, 3, 78-85 (2006)

5. M. I. Gaidar, Psychologist in modern society: from education to professional activity, 51-63 (2007)

6. F. O. Semenova, Fundamental research, 11-4, 918-923 (2014)

7. F. A. Babanova, Innovative technologies in training and education. Proceedings of the 10th International scientific conference, 76-79 (2016)

8. A. S. Ognev Theoretical foundations of psychology subjectivity Genesis (RAGS under the President of the Russian Federation, Voronezh, 1997)

9. C. R. Panteleev Technique of research of self-evaluation (Smysl, Moscow, 1993) 